\title{
Estudio de factibilidad para la determinación de nitrógeno y proteína mediante el uso del calorímetro diferencial adiabático
}

\author{
GABRIELA PÁEZ ${ }^{*}$, PABLO BONILLA' \\ 'Facultad de Ciencias Químicas, \\ Universidad Central del Ecuador (UCE), Ciudadela Universitaria. Av. América, Quito. \\ *Correspondencia: gabbylu84@hotmail.com
}

Recibido: 07 de mayo de 2015, Aceptado: 13 de septiembre de 2015

\section{Resumen}

La bomba calorimétrica permite medir el contenido calórico de alimentos, ésta posee una camisa de agua que absorbe el calor liberado por la combustión del alimento. El calor que absorbe el agua, no proviene únicamente de la combustión del alimento, sino que intervienen otros factores como el calor de formación del $\mathrm{HNO}_{3}$. Este ácido se forma porque el nitrógeno presente en el alimento y aire es oxidado $\mathrm{N}_{2} \mathrm{O}_{5}$ el mismo que reacciona con el agua y forma $\mathrm{HNO}_{3}$. El objetivo de esta investigación fue aprovechar la formación $\mathrm{HNO}_{3}$ para cuantificar la cantidad de nitrógeno presente en el alimento y determinar sus proteínas. La factibilidad de determinar nitrógeno usando el calorímetro está sujeta a varios factores que impiden la cuantificación exacta de nitrógeno. Estos factores son limitaciones propias del aparato y complejidad de la muestra analizada. A pesar de estos inconvenientes, se obtuvo buenos resultados con muestras de suplementos nutricionales y harina de maíz que presentaron valores de nitrógeno muy similares a los obtenidos por el método oficial Kieldah. Para alcanzar ésta similitud, se cambió algunos parámetros como mezclar la muestra con ácido benzoico y cuantificar el $\mathrm{HNO}_{3}$ formado con una base $0.02 \mathrm{~N}$.

Palabras clave: nitrógeno, proteína, calorímetro.

\section{Feasibility study for the determination of nitrogen and protein by using the adiabatic differential calorimeter}

\begin{abstract}
The bomb calorimeter allows measure the caloric content's food, it has a water jacket to absorb the heat released by the combustion food. The heat absorbed by water not only comes from the combustion food, but also other factors such as heat of formation of nitric acid. This acid is formed because the nitrogen present in the food and air is oxidized $\mathrm{N}_{2} \mathrm{O}_{5}$, it reacts with water to form $\mathrm{HNO}_{3}$. The objective in this investigation consists of use the formation of $\mathrm{HNO}_{3}$ to quantified the amount of nitrogen present in the food and know their protein percent. The feasibility of determining nitrogen using the adiabatic calorimeter it is subject to several factors that prevent accurate quantification exactly of nitrogen. These factors are; limitation's device and complexity of the sample analyzed. Despite these drawbacks, good results were obtained with sample's supplements nutritional. Value's Nitrogen of these samples are very similar to the values obtained by the official method Kjeldah. To achieve this similarity, some parameters are changed as mixing the sample with benzoic acid and quantify $\mathrm{HNO}_{3} 0.02 \mathrm{~N}$ formed with a base.
\end{abstract}

Key words: nitrogen, protein, adiabatic calorimeter. 


\section{Introducción}

La bomba calorimétrica es utilizada para determinar el calor de combustión de varias sustancias cuando se queman a volumen constante. Para el análisis del calor de combustión de una sustancia sólida, ésta deberá colocarse en forma de pastilla dentro de la bomba, adicionalmente se agrega el oxígeno necesario para la combustión.

Este tipo de calorímetro se rodea de una camisa de agua que absorberá el calor liberado por la sustancia; esto se realiza dentro de una camisa adiabática para evitar pérdida de calor que afecte al proceso. Sin embargo, el calor que absorbe el agua no solo es debido a la combustión de la sustancia, sino a otros factores, entre los cuales pueden nombrarse: liberación de calor del alambre que provoca el encendido de la muestra, liberación de calor por la formación de ácido nítrico y sulfúrico, entre otros.

Al aplicar la ecuación de la Primera Ley de la Termodinámica al proceso de combustión a volumen constante y tomando en cuenta todos los factores mencionados anteriormente, se obtiene la siguiente ecuación:

$$
H_{g}=\frac{\left(t W-e_{1}-e_{3}\right)}{g}
$$

Donde:

$H_{g}=$ calor de combustión bruto; $(\mathrm{cal} / \mathrm{g})(1 \mathrm{cal} / \mathrm{g}=4.1868 \mathrm{~J} / \mathrm{g})$

$t=\quad$ cambio de temperatura en la combustión; $\left({ }^{\circ} \mathrm{C}\right)\left(t=t_{f}-t_{0}\right)$

$W=$ equivalente de energía del calorímetro; (cal/ ${ }^{\circ} \mathrm{C}$ ) ( $\left./{ }^{\circ} \mathrm{K}\right)$

$e_{1}=$ corrección por el calor de formación del ácido nítrico $\left(\mathrm{HNO}_{3}\right)$; (cal) (1 cal=4.1868 J); también equivale a los mililitros de solución álcali utilizados en la titulación ácido-base.

$e_{3}=$ corrección por el calor de combustión del alambre de ignición; (cal) ó (J)

$g=\quad$ peso de la muestra (g) [1].
El factor $e_{2}$, corrección del ácido sulfúrico, es importante en el caso de combustibles, pero para alimentos el contenido de azufre es insignificante por lo que se elimina de la ecuación.

El valor $e_{1}$ representa el calor de formación del ácido nítrico; éste se origina por la alta presión de oxígeno existente en el interior de la bomba que ocasiona que el nitrógeno proveniente de la muestra o del aire se oxide a óxido nítrico $\left(\mathrm{N}_{2} \mathrm{O}_{5}\right)$, el mismo que al combinarse con el agua forma el ácido nítrico $\left(\mathrm{HNO}_{3}\right)$.

Para conocer el factor de corrección del ácido nítrico $\left(e_{1}\right)$ se valora el líquido de lavado de la bomba con un álcali [1].

Al determinar la cantidad de ácido nítrico formado en la combustión, se conocerá el contenido de nitrógeno de la muestra y a su vez el porcentaje de proteína.

\section{Parte experimental}

\subsection{Materiales}

- $\quad$ Calorímetro adiabático (PARR 1976)

- $\quad$ Bomba de combustión 1108

- $\quad$ Termómetro digital (FISHER SCIENTIFIC)

- $\quad$ Plancha calefactora (THERMOLYNE TYPE 1000)

- Balanza analítica (METTLER Ac 100)

- Tanque de oxígeno (AGA)

- $\quad$ Potenciómetro (METTLER)

- Molino eléctrico (MLW)

\subsection{Métodos}

Se utilizó el método estandarizado ASTM D 240-64 correspondiente para ensayos en el calorímetro adiabático, con las respectivas modificaciones para lograr determinar el contenido de nitrógeno de la muestra. Se

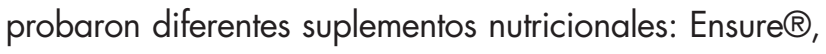


Pediasure $\AA, \quad$ Colada Nutrinfa $\AA$ y harina de maíz y se midió el contenido de nitrógeno por el método oficial de Kjeldahl y el calorimétrico.

Procedimiento:

\section{a) Preparación de la muestra:}

Se pesó cantidades iguales de muestra y ácido benzoico.

Se mezcló y trituró en un mortero eléctrico.

Se comprimió esta mezcla (muestra más ácido benzoico) en forma de pastillas de $1 \mathrm{~g}$.

\section{b) Alambre de ignición:}

- Se cortó un fragmento del alambre de ignición (Fe) entre 10-11 centímetros y se pesó.

- Se envolvió el alambre alrededor de la pastilla y se pesó.

- Se conectó a los electrodos de la bomba calorimétrica el alambre más la pastilla.

- Se colocó $1 \mathrm{ml}$ de agua destilada dentro de la bomba y se cerró herméticamente.

\section{c) Introducción de oxígeno:}

- Se llenó la bomba con 25 atmósferas de presión de oxígeno.

\section{d) Montaje del calorímetro:}

- Se llevó la bomba al recipiente calorimétrico, el mismo que contiene $2000 \mathrm{ml}$ de agua destilada a $25^{\circ} \mathrm{C}$ y que está dentro de la camisa adiabática.

- Se colocó el agitador, el termómetro y en la tapa los bornes del dispositivo de suministro de energía eléctrica.

\section{e) Encendido:}

- Se cerró la tapa de la camisa adiabática y se encendió el agitador para alcanzar el equi- librio térmico entre los distintos componentes del sistema.

- Se encendió la bomba, una vez que se llegó al equilibrio entre la temperatura del agua (2000 mL) y el calorímetro, presionando el botón de ignición para dar inicio a la combustión de la muestra.

- $\quad$ Se registraron los valores de temperatura cada 30 segundos hasta que no presentó cambios.

- Se apagó el calorímetro.

\section{f) Desmontaje del aparato:}

- Se retiró la bomba y se dejó evacuar los gases de su interior mínimo 1 minuto.

- Se lavó con agua destilada las paredes de la bomba y sus electrodos.

- Se filtró el agua de lavado.

\section{g) Determinación de nitrógeno [2]}

- Se determinó el error de formación del ácido nítrico, titulando el agua de lavado con $\mathrm{NaOH}$ $(0.02 \mathrm{~N})$ y el indicador fenoftaleína.

- Se determinó la cantidad de nitrógeno utilizando la siguiente relación:

$$
\begin{aligned}
& \mathrm{C}_{\mathrm{NaOH}} \times \mathrm{V}_{\mathrm{NaOH}}=\mathrm{C}_{\mathrm{HNO} 3} \times \mathrm{V}_{\mathrm{HNO} 3} \\
& \text { \#eq g NaOH}=\text { \#eq g HNO } \\
& \text { \#eq g HNO } \\
& 3=\mathrm{C}_{\mathrm{NaOH}} \times \mathrm{V}_{\mathrm{NaOH}} \\
& \text { \#eq g } \mathrm{HNO}_{3} \rightarrow \mathrm{gHNO}_{3 \text { total }} \\
& \mathrm{gHNO}_{3} \text { corrido }=\mathrm{gHNO}_{3} \text { total }-\mathrm{gHNO}_{3} \text { ac.benzoico } \\
& \mathrm{gHNO}_{3} \approx \text { gN } \\
& \% \text { Proteína }=\mathrm{N} \times 6.25
\end{aligned}
$$

* Nota: El ácido benzoico no tiene nitrógeno en su estructura, sin embargo, su presencia contribuye a aumentar la temperatura favoreciendo la oxidación del nitrógeno. 


\section{Resultados y discusión}

\subsection{Resultados}

En la Tabla 3.1 se presenta el contenido de proteínas determinado por el método calorimétrico y en la Tabla 3.2 por el método de Kjeldahl.

Tabla 3-1 Determinación de nitrógeno por el método calorimétrico

\begin{tabular}{lccc}
\hline Muestra & Determinaciones & $\begin{array}{c}\text { Nitrógeno } \\
\mathbf{( g )}\end{array}$ & $\begin{array}{c}\text { \%Proteína } \\
\mathbf{( N \times 6 . 2 5 )}\end{array}$ \\
\hline Ensure $\AA$ & 6 & $2.52 \pm 0.02^{a}$ & $15.74 \pm 0.10^{a}$ \\
Pediasure ${ }^{\circledR}$ & 6 & $2.45 \pm 0.02^{a}$ & $15.29 \pm 0.12^{a}$ \\
Colada Nutrinfa ${ }^{\circledR}$ & 6 & $2.08 \pm 0.05^{a}$ & $13.01 \pm 0.28^{a}$ \\
Harina de maíz & 6 & $1.65 \pm 0.03^{a}$ & $10.31 \pm 0.17^{a}$ \\
\hline
\end{tabular}

${ }^{a}$ Desviación estándar

Tabla 3-2 Determinación de nitrógeno por el método de Kieldahl

\begin{tabular}{lcc}
\hline \multicolumn{1}{c}{ Muestra } & Nitrógeno $(\mathbf{g})$ & $\begin{array}{c}\text { \% Proteína } \\
\text { (N x 6.25) }\end{array}$ \\
\hline Ensure ${ }^{\circledR}$ & 2.54 & 15.85 \\
Pediasure ${ }^{\circledR}$ & 2.47 & 15.44 \\
Colada Nutrinfa ${ }^{\circledR}$ & 2.12 & 13.25 \\
Harina de maíz & 1.68 & 10.50 \\
\hline
\end{tabular}

\subsection{Análisis estadístico}

Para determinar la igualdad o diferencia entre los valores obtenidos con el método calorimétrico y el método de Kjeldahl, se planteó la siguiente hipótesis de trabajo:

Ho: Nitrógeno ${ }_{(\text {Kieldahl) }}=$ Nitrógeno $_{\text {(calorimetría) }}$

Hi: Nitrógeno ${ }_{(K \text { jeldahl) }} \neq$ Nitrógeno $_{\text {(calorimetría) }}$

Se calculó el valor " $\mathrm{t}$ " de student correspondiente a la comparación de la media de la muestra (método calorimétrico) con un valor teórico (método de Kjeldahl), Tabla 3.3

$$
t=\frac{|\mu-\bar{x}|}{\frac{s}{\sqrt{n}}}
$$

$\bar{x}=\quad$ valor medio de la muestra

$\mu=\quad$ valor teórico de la muestra

$S=\quad$ desviación estándar

$n=\quad$ número de valores

Tabla 3-3 Valores de " $t$ " de student

\begin{tabular}{lll}
\hline \multicolumn{1}{c}{ Muestra } & $\mathbf{t}_{\text {calulado }}$ & $\mathbf{t}_{\text {Teórico (dos colas 95\%) }}$ \\
\hline Ensure® & 2.24 & 2.57 \\
Pediasure ${ }^{\circ}$ & 2.24 & 2.57 \\
Colada Nutrinfa® & 1.79 & 2.57 \\
Harina de Maíz & 2.24 & 2.57 \\
\hline
\end{tabular}

\subsection{Discusión}

El análisis estadístico de la prueba † al 95\%, indicó que los valores de $t_{\text {caluado }}$ son menores que el valor de $t_{\text {Teórico }}$. Es decir, que no existe diferencia significativa entre los valores que se obtuvieron por el método calorimétrico y el método Kieldahl.

Por tanto, se aceptó la hipótesis nula:

Ho: Nitrógeno ${ }_{(K \text { ieldahl) }}=$ Nitrógeno $_{\text {(calorimetría) }}$

\section{Conclusiones}

- El ácido benzoico añadido a la muestra contribuye a incrementar la temperatura de combustión y obtener valores de nitrógeno similares entre sí, con desviaciones estándar bajas. 
- En las muestras de harina de maíz, Ensure ${ }^{\circledR}$, Pediasure $\AA$ y Colada Nutrinfa $\AA$ las condiciones de oxidación de la bomba calorimétrica fueron adecuadas para lograr el rompimiento de los enlaces de sus componentes y liberar el nitrógeno presente. Por esta razón, se obtuvo valores similares a los de Kjeldahl.

- La aplicación del método calorimétrico como una alternativa para determinar nitrógeno y proteína en los alimentos no puede ser generalizada. Debido a que para muestras más complejas se requiere condiciones más ex- tremas de temperatura, lo que implicaría un cambio en el diseño del aparato.

\section{Agradecimientos}

Los autores agradecen a la Universidad Central del Ecuador, en especial a la Facultad de Ciencias Químicas, por facilitar sus laboratorios, materiales y equipos para la realización de esta investigación. El primer autor agradece al Dr. Pablo Bonilla por brindarle la oportunidad de trabajar con él y beneficiarme de sus conocimientos.

\section{Referencias}

[1] ASTM (1973). D240-64: Standard Method of Test for Heat of Combustion of Liquid Hydrocarbon Fuels by Bomb Calorimeter. (Volume 05.01) Petroleum Products Liquid Fuels, and Lubricants. USA.

[2] R. Stout, F. Nettleton \& L. Price. (1985). Bomb calorimetry: The energy content of pizza. Journal of Chemical Education, $62(5), 438$. 